\title{
Ritual e narrativa
}

\author{
A supplicatio no mito da Fortuna Muliebris \\ (Dionísio de Halicarnasso, Antiquitates Romanae, 8. 39.1-53.1)
}

\section{Ritual and Narrative}

The supplicatio in the Myth of Fortuna Muliebris

(Dionysius of Halicarnassus, Antiquitates Romanae, 8. 30.1-53.1)

\section{Claudia Beltrão Rosa}

Departamento de História

Universidade Federal do Estado do Rio de Janeiro

Av Pasteur, 458, s. 17, Urca, Rio de Janeiro, RJ, 22.290-240, Brasil

crbeltrao@gmail.com

RESUmo Mitos e rituais criam e reforçam os laços entre indivíduos e comunidade, legitimando o grupo e a autoridade, envolvendo o potencial mimético das performances. O principado augustano foi um momento rico de criação e de ressignificação de rituais e de mitos, expressos em ações e intervenções espaciais e numa literatura cuja observação permite uma via de acesso à compreensão do sistema de valores, do uso das tradições e das inovações no espaço público romano. Este artigo tratará da etiologia do santuário da Fortuna Muliebris na versão de Dionísio de Halicarnasso. As narrativas etiológicas da Fortuna Muliebris são um dos elementos mais significativos para a análise do sistema de valores e das distinções de gênero na Roma augustana, e estarão em pauta elementos verbais e visuais da performance das personagens, interessando à análise elementos vinculados a normas e tradições do ritual da supplicatio.

Palavras-Chave Dionísio de Halicarnasso, Fortuna Muliebris, mito e ritual.

\footnotetext{
Recebido 15 de maio de 2014 | Aprovado 25 de julho de 2014

http://dx.doi.org/10.1590/0104-87752015000100008

Varia Historia, Belo Horizonte, vol. 31, n. 55, p. 193-220, jan/abr 2015
} 
Abstract Myths and rituals create and reinforce the links between individuals and community and legitimize authority, involving the mimetic potential of performances. The Augustan principate was plenty of creation and recreation of rituals and myths, expressed in actions, spatial interventions, and a literature whose analysis can give us important keys to the understanding of the system of values, the use of traditions and innovations in Roman public space. This paper focus on the etiology of Fortuna Muliebris according to Dionysius of Halicarnassus. The narratives of Fortuna Muliebris are significant for the analysis of the system of values and gender roles in Augustan Rome, and verbal and visual elements of the performance of the characters are linked to norms and traditions the ritual of supplicatio.

KeYwORDS Dionysius of Halicarnassus, Fortuna Muliebris, myth and ritual.

Ali, ela permanece por longo tempo, seus olhos mirando a terra; Ela derrama suas lágrimas, e excita a compaixão em todos os corações.

(Dionísio de Halicarnasso)

O estudo da religião romana, em seus elementos, práticas rituais e em suas narrativas associadas, é um viés possível para a compreensão das representações identitárias romanas, criando e transmitindo conteúdos sobre Roma e sobre os romanos, reconhecíveis por toda a comunidade e passíveis de veiculação a outras comunidades, permitindo analisar a construção e a recepção de significados sobre o mundo e sobre a sociedade. Nas últimas décadas, estudiosos da religião romana conseguiram, paulatinamente, ultrapassar barreiras historiográficas provenientes, regra geral, de incompreensões e dificuldades teóricas, religiosas e ideológicas que prejudicavam a pesquisa das religiões antigas. O estudo das religiões antigas, especialmente da religião romana, é uma das mais férteis áreas dos estudos da antiguidade e, atualmente, poucos historiadores desconsideram o potencial das pesquisas sobre as religiões e os sistemas 
religiosos para a lide historiográfica. As religiões dizem respeito não apenas a sentimentos ou percepções individuais, mas aos grupos sociais, sendo um dos principais fatores que instituem, consolidam, transformam e mantêm o sistema de valores, a coesão e o ordenamento social, representando-os como uma ordem sagrada (Paden, 1996, p.3-18).

Sob este aspecto, a análise de rituais religiosos romanos pode ser considerada profícua para a construção do conhecimento sobre a antiguidade. Os rituais religiosos romanos podem ser analisados como mecanismos que sacralizavam o ordenamento político e social da urbs, estabelecendo o lugar de cada coisa e de cada ser na cidade, bem como suas relações com o "mundo exterior". Considerar os rituais como ótimos índices para a análise, por reunirem comunicação e performance e por veicularem diversos conteúdos que, reiterados no tempo e no espaço, são agregados ao universo cognitivo e afetivo de seus participantes - oficiantes ou espectadores -, reafirmando ou alterando uma determinada visão de mundo e de ordem social, é percebê-los como um fenômeno social. Rituais reforçam os laços entre indivíduo e comunidade, legitimando o grupo e a autoridade, envolvendo o potencial mimético das performances - o drama, os atores, os espectadores, os gestos, os sons, as palavras, os objetos - comunicando, reforçando e consolidando laços sociais, hierarquias políticas, ideias, ideais, aspirações e valores compartilhados, assim como instituindo e legitimando mudanças e inovações.

Algumas ideias de Clifford Geertz, Stanley Tambiah, Catherine Bell, Mary Douglas e Jonathan Z. Smith são fundamentais para esta análise. ${ }^{1}$ Para esses estudiosos, os rituais são formas altamente eficazes de comunicação simbólica, e seus participantes - oficiantes e espectadores - ao compartilharem, pelos diversos processos educacionais, formais e informais, de valores e significados comuns, podem compreender os significados veiculados pelas ações rituais, mesmo que tal compreensão seja polissêmica. Rituais não veiculam uma única mensagem e seus emissores podem ser diversos, bem como a compreensão dos significados pode

1 As referências principais para as considerações que se seguirão são: GEERTZ, 2008, p.65-91; TAMBIAH, 1985; BELL, 2009; BELL, 1992; DOUGLAS, 1996 e SMITH, 1992. 
não ser igual entre os participantes, mas gestos, objetos e palavras comunicam ideias, aspirações, distinções etc., que potencialmente podem ser compreendidas. A performance ritual é uma metalinguagem para os participantes, e Tambiah, por exemplo, cita a repetição que reitera os elementos do culto, criando a expectativa (Tambiah, 1985, p.133). Douglas, por sua vez, considera a formalidade e a repetição como convenções que criam a ordem, enquanto Smith as considera convenções que criam a impressão de ordem. ${ }^{2}$

$\mathrm{O}$ aparato e a performance ritual, portanto, são poderosos meios de se consolidar e reiterar a ordem social, vinculando seus participantes a um modo de ver e sentir as coisas, a autoridade, as hierarquias, as distinções sociais, e Catherine Bell, insistindo sobre a importância da análise do vocabulário e das ações rituais, relevando sua eficácia ao levar os grupos humanos a assunções sobre a "ordem das coisas" e sobre seu "lugar" nesta ordem, chama a atenção também para as fórmulas arcaizantes, mesmo quando há novos elementos no ritual, ou seja, quando se trata de um novo ritual, ajudando a separar o momento do ritual de outras experiências da vida quotidiana (Bell, 2009, p.160). Imagens e emoções apresentadas, criadas e despertadas no ritual criam, em suma, ideias e modos de ver e perceber a realidade.

Rituais religiosos independem dos mitos que eventualmente lhes são associados. Contudo, quando rituais e mitos convergem, criam instrumentos cognitivos pelos quais o mundo da experiência é interpretado, fornecendo normativas de ação e de pensamento para as comunidades em seu presente e para o futuro. Tais mitos potencializam o efeito das

2 Destaque-se uma coerente definição de ritual de Stanley Tambiah que fornece uma boa base para a análise de rituais religiosos romanos: "Ritual é um sistema culturalmente constituído de comunicação simbólica. É constituído de sequências padronizadas e ordenadas de palavras e atos, frequentemente expressos em media múltiplos, cujo conteúdo e arranjo são caracterizados em vários graus pela formalidade (convencionalidade), estereotipia (rigidez), condensação (fusão) e redundância (repetição)" (TAMBIAH, 1985, p.128). Essas ideias podem ser complementadas pela definição de Daniel Gargola: "(Ritual é)uma forma de comunicação simbólica, disseminando uma representação idealizada da comunidade, de sua liderança, suas unidades constituintes, as relações necessárias entre elas e o lugar de tudo e de cada coisa no mundo" (GARGOLA, 1995, p.6). 
performances rituais e, para John Scheid, as etiologias transcrevem o rito em narrativa, explorando um ou outro aspecto do culto ou do festival para produzir narrativas e especulações sobre suas origens, que são aplicadas à tradição ritual ou a algum de seus elementos (Scheid, 2003, p.126).

Analisar mitos é uma ação cujo interesse variou (e varia) ao longo dos tempos, e o mito é um objeto de pesquisa muito complexo, especialmente porque se criou um "mito moderno" de que o mito é a antítese da história. Esta visão moderna é, no mínimo, superficial e redutora, se não equivocada. Transformar dados da realidade vivida em mito é um traço fundamental da sociedade romana que podemos detectar em momentos diversos de sua trajetória no tempo e no espaço, pelo que desconsiderar o mito na pesquisa é arriscar deixar escapar elementos centrais da experiência coletiva antiga. E, neste ponto, o principado augustano é um momento ímpar para a análise. Trata-se de um momento rico de criação e de ressignificação de rituais e de mitos, principalmente no que tange aos sacra publica, ${ }^{3}$ expressos em ações rituais, intervenções espaciais e numa literatura cuja observação permite uma via de acesso à compreensão do sistema de valores, do uso das tradições e das inovações no espaço público romano. Observando as considerações de Mary Beard,

3 A distinção entre sacra publica e sacra priuata fornecida por Festo é um guia para a compreensão dos sacra romanos: "Os ritos públicos são aqueles realizados a expensas públicas em benefício do povo (...) em contraste com os ritos privados que são realizados em benefício de indivíduos, das famílias, dos descendentes" (Publica sacra, quae publico sumptu pro populo fiunt quaeque pro montibus pagis curis sacellis; at priuata, quae pro singulis hominibus familiis gentibus fiunt: 350L). Sacra priuata, como podemos depreender, não eram apenas os ritos da religio domestica, mas tudo o que não se inseria na definição de publica sacra, ou seja, os ritos realizados em benefício do povo romano (pro populo), por oficiantes sancionados e financiados pelo tesouro público, com participação ativa de magistrados e sacerdotes, diante da grande massa do público assistente, que geralmente participava - no todo ou em parte - do banquete após o sacrifício e em outras ações, e.g., nas grandes procissões que caracterizavam as supplicationes. A própria definição de sacrum é reservada para coisas e lugares consagrados oficialmente pelos pontífices (cf. Gaio. Inst. 2,5; Ulpiano, Dig. I, 8.9.). Podemos assumir que a definição de sacra - ao menos juridicamente - seguia os mesmos passos que definiam o ritual público, ou seja, um objeto ou lugar que se tornava sagrado através de um ato ritual específico - a consecratio - que devia ser autorizado pelo Senado, presidido por sacerdotes e magistrados e promovido com fundos públicos. 
(...) compreendo que os festivais do calendário ritual, junto com as narrativas etiológicas a eles associadas, ofereciam aos participantes romanos, ano após ano, séries de quadros evocando diferentes momentos da religião e da história romanas. Ou seja, cada festival, com todas as suas diferentes associações, apresenta e representa uma imagem da romanidade - unindo o passado ao presente, e reunindo aspectos aparentemente diversos da religião romana e da tradição cultural. Em certo sentido, o calendário ritual como um todo pode ser visto como um espetáculo conceitual de Roma e do que é ser romano (Beard, 2003, p.281) (grifo da autora).

Os mitos etiológicos são, portanto, um dos instrumentos pelos quais os conhecimentos religiosos são adquiridos, ao fornecerem explicações e interpretações dos rituais que, publicizadas através de diversos media, incrementam os processos de codificação e comunicação de postulados e de conhecimentos religiosos, consolidando formas autorizadas de crenças e rituais e o estabelecimento de hierarquias, incrementando a dinâmica dos sistemas religiosos, que implica comunicação de seus conteúdos. ${ }^{4} \mathrm{O}$ conhecimento religioso codificado na linguagem verbal e em versões escritas é uma ótima ferramenta na construção de sistemas religiosos de larga escala e expansíveis a outros grupos humanos externos ao seu locus original, com variações regionais, decerto, mas sem perder suas características principais, como ocorreu no imperium romanum (Whitehouse, McCauley, 2005; Whitehouse, Martin, 2004).

4 Como foi pontuado recentemente: "Em relação à documentação literária, atualmente podemos definir algumas tendências da historiografia internacional da religião romana antiga: uma tendência cética em relação à obtenção de qualquer conhecimento seguro sobre o período arcaico romano, e uma tendência mais otimista que se apoia nos estudos da etimologia e do ritual, renovando o interesse pela releitura das fontes textuais. Desse modo, acreditamos que a análise da documentação literária pode ser profícua para o estudo da religião romana. Esses textos trazem, nitidamente, alguns elementos de fundo arcaico (cf. D. Hal. 7, 70, 2-3: tas archaias kai topicas historias), que sobreviveram não fossilizados, ou seja, num contexto dinâmico, pois cada geração reconstituía e ressignificava o ritual e o mito. Certamente, o registro literário nos apresenta tais rituais num momento tardio de seu desenvolvimento, ou mesmo em sua recuperação pela restauratio augustana, mas também - e isso dificulta a pesquisa - validava novos cultos e práticas inovadoras com referência a antigas tradições religiosas" (BELTRÃO, 2011, p.85). 
Os relatos históricos e literários do período augustano são plenos de mitos etiológicos que, lançando mão de personagens e ações explicavam e interpretavam as ações rituais e a topografia sagrada da urbs, veiculando, ao mesmo tempo, conteúdos centrais da chamada restauratio augustana. Tais mitos, junto com os rituais, criavam a história e a identidade romanas no período augustano e, a fim de explorar alguns dos variados meios pelos quais a experiência e os conteúdos religiosos foram organizados, transmitidos e politizados em termos de representações culturais, dentre os diversos mitos criados e veiculados pela literatura augustana, este artigo tratará de um em particular, o mito etiológico do santuário da Fortuna Muliebris na versão do historiador grego Dionísio de Halicarnasso, no L. 8 de suas Antiquitates Romanae. Este mito foi vinculado, no século I a.E.C., ao épico do Coriolano e das guerras contra os volscos e há muito se discute o significado, o valor, a cronologia e a historicidade do episódio, mas, seja qual for sua conexão com a luta contra os volscos, no que tange ao templo da Fortuna Muliebris, é possível que a ligação do templo com esse episódio seja uma criação tardia. ${ }^{5}$ As narrativas etiológicas da Fortuna Muliebris são um dos elementos mais significativos para a análise do sistema de valores e das distinções de gênero na Roma augustana, e neste capítulo estarão em pauta elementos verbais e visuais da performance das principais personagens envolvidas nas cenas de 8.39.1 a 8.53.1, interessando à análise elementos vinculados a normas e tradições da práticas ritual romana da supplicatio.

\section{O santuário da Fortuna Muliebris}

O templo da Fortuna Muliebris era um dos muitos espaços sagrados oficiais da Roma augustana. Cultos eram celebrados nesses santuários e o programa ritual incluía procissões, criando ou reforçando rotas que, monumentalizadas, estavam diretamente ligadas à expressão de conteúdos da identidade romana. As procissões de diversos tipos podem ser consideradas excelentes meios para centralizar uma topografia urbana

5 BELTRÃO, Constructing sacred boundaries to Rome, no prelo; BELTRÃO, 2013, p.108-126. 
complexa e para, simultaneamente, publicizar o próprio ritual. Os diversos elementos do culto, ou seja, seus ritos, seus lugares e objetos sagrados, sua entrada no calendário etc., criavam significados complexos que precisam ser levados em conta pela pesquisa. O mito, por sua vez, conectava os monumentos religiosos, o culto e a memória da urbs.

A paisagem religiosa,${ }^{6}$ e mesmo a monumental romana, constrói uma série de contrastes e oposições entre homens/mulheres, masculino/feminino, interior/exterior etc., binômios contrários e complementares, criados pela tradição dos diferentes aspectos da bipolarizada imago mundi oficial romana. É importante, portanto, atentar para as diversas interpretações, etiologias e tentativas de definições feitas pelos autores antigos sobre as tradições religiosas e sobre as inovações na tradição.

Localizado na IV milha da Via Latina, o templo da Fortuna Muliebris é tradicionalmente classificado como um dos santuários de fronteira, associado à mais antiga fronteira de Roma, o ager romanus antiquus. ${ }^{7}$ O quão pertinente é o conceito de santuário de fronteira e a discussão do caráter arcaico do ager romanus antiquus são temas que escapam aos propósitos deste texto. ${ }^{8}$ Importa, neste momento, que no período augustano, o templo foi "restaurado" por Lívia, e seus ritos foram associados, pelos escritores, a um épico da fundação da República, o episódio do Coriolano.

O episódio do Coriolano é de elaboração literária tardia, e sua interpolação com a etiologia da fundação do templo da Fortuna Muliebris é, possivelmente, uma invenção augustana. A consolidação - ou a invenção - do mito etiológico deve-se, especialmente, a dois historiadores

6 Compreendo paisagem religiosa como uma construção simbólica e dinâmica do espaço por meio da ação conjunta da performance dos rituais e da pragmática poética dos mitos e narrativas, de acordo com as propostas de J. Scheid e F. de Polignac, que apresentam o conceito de paisagem religiosa como uma leitura simbólica do espaço, entendida simultaneamente "em sua materialidade visível e, metaforicamente, como o espectro de identidades religiosas múltiplas e negociadas" (SCHEID, DE POLIGNAC, 2010, p.430).

7 cf. ALFÖLDI, 1965; QUILICI-GIGLI, 1981, p.547-563; SCHEID, 1987, p.583-595; CIFANI, 2005, p.199-221.

8 cf. ZIÓLKOWSKI, 2009, p.91-130; BELTRÃO, no prelo. 
augustanos, Tito Lívio e Dionísio de Halicarnasso, que criaram as bases a partir das quais associações e desenvolvimentos literários posteriores foram realizados, criando uma tradição com pequenas variações de nomes de personagens, mas cujo conteúdo central é o seguinte: exilado de Roma devido a questões que se vinculam ao épico das lutas entre patrícios e plebeus (um dos tópicos centrais da literatura augustana), Caio Márcio, o Coriolano, jovem patrício e general vitorioso da ilustre gens dos Marcii, descendentes de Anco Márcio e de Numa Pompílio, entra em conflito com os líderes plebeus e é exilado, recebendo auxílio dos volscos, com quem se compromete por juramento e, assumindo o comando do exército volsco, ameaça Roma, acampando na $\mathrm{V}$ milha da urbs, nas Fossae Cluiliae, ${ }^{9}$ com um exército superior ao dos romanos em número e em força. Embaixadas diplomáticas de magistrados, senadores e sacerdotes não foram bem-sucedidas e o perigo era premente. Nesse momento, as narrativas põem em cena uma multidão de matronae que, lideradas por Vetúria (a mãe do Coriolano) e Volumnia (a esposa), em Tito Lívio, entre as quais Dionísio acrescenta Valéria, irmã de Valério Publícola (um dos "libertadores" de Roma da "tirania" dos Tarquínios) como idealizadora da ação, decidem o futuro da urbs. Conseguindo evitar o conflito entre romanos e volscos, as matronae obtêm, como recompensa, o direito de erguer um templo à Fortuna Muliebris (T. Lívio II. 40, 103; Dion. Hal., 8. 39.1-56.4) no local onde teria ocorrido o encontro das matronas com o Coriolano e o exército volsco. O Senado garantiu a construção do templo pelas matronas, mas recusou-lhes o direito de dedicarem ${ }^{10} \mathrm{o}$ templo, o que foi feito pelos pontífices, mas lhes permitiu

9 As Fossae Cluiliae formavam uma grande trincheira que circundava Roma a cerca de 6-8 km da cidade, e acreditava-se ser o local das guerras contra a lendária Alba Longa, dos Horácios e Curiácios e do Coriolano (referências às Fossae Cluiliae como "fronteira de Roma": T. Lívio. I. 23.3; 2.39.45; Dion Hal., 3. 41; Plut. Cor. 30,1).

10 A dedicatio era controlada pelas regras do ius sacrum. Segundo Beard, North e Price, para além do dedicante, “(...) os sacerdotes, o senado e os censores estavam envolvidos e a ação pública final de dedicar o tempo ao deus ou deusa era cuidadosamente controlada por regras, incluindo uma moção para um voto do povo, autorizando o ato de dedicação" (BEARD, NORTH, PRICE, 1998, p.88). 
selecionar a sacerdotisa do novo culto. Valéria teria sido a primeira sacerdotisa do culto, e as matronas conseguiram a permissão senatorial para, em acréscimo à celebração oficial do dies natalis do templo (6 de julho), celebrarem também o aniversário do afastamento do Coriolano do ager romanus ( $1^{\circ}$ de dezembro). ${ }^{11}$ Além disso, quando o templo estava pronto, as matronas dedicaram extraoficialmente sua própria estátua da deusa, ao lado daquela que fora paga e dedicada pelos senadores. $\mathrm{E}$ a segunda estátua, numa epifania, disse às matronas que elas fizeram sua dedicação de acordo com o desejo divino (cf. Dion. Hal., 8. 56. 2-3; Plut. Cor. 37.3; Val. Max. 1.8.4).

Todos os autores convergem na ideia de que o Coriolano era orgulhoso e que as embaixadas (magistrados, senadores, sacerdotes) foram em vão, e ressaltam o papel central conferido à intervenção das matronae no bom sucesso de Roma. As personagens são matronae, um termo reiterado e que se vincula a um estatuto social dotado de prestígio social: elas são esposas legítimas e mães de cidadãos. ${ }^{12}$ E convergem, igualmente, no fato de que inscrevem suas narrativas etiológicas no

11 A observação do significado da data do festival ultrapassa os limites deste artigo; sem fazer referência ao aniversário do afastamento dos volscos do território romano, note-se, simplesmente, que a data da comemoração da fundação do templo da Fortuna Muliebris refere-se à "restauração" por Lívia, e que está significativamente inserida entre o festival das Poplifugia, no dia 5 de julho, e o das Nonae Caprotinae, em 7 de julho, concomitantes, também, à realização dos ludi Apollinares, entre 6 e 13 de julho. O principado augustano promoveu, também, um sacrifício a Consus, divindade romuleana por excelência e vinculado ao tema do rapto das Sabinas, no mesmo dia da comemoração da Fortuna Muliebris. Esses rituais e festivais, inter-relacionados por mitos etiológicos, por sua posição no calendário ritual e vinculação a marcos espaciais, são altamente politizados no período tardo-republicano e augustano.

12 A declaração de Nicole Boëls-Janssen é esclarecedora em relação às personagens: "A sociedade romana é uma sociedade muito estruturada, dividida em classes de idade, categorias sexuais, categorias sociais nitidamente delimitadas (...). Quanto à classe social, ela certamente tem grande importância, mas a mulher não faz parte dela senão por intermédio de um homem, pai ou marido. O casamento pode mesmo, eventualmente, a desclassificar: é o caso da patrícia Virgínia, que foi excluída do culto da Pudicitia por ter se casado com um plebeu. A única categoria que era nitidamente reconhecida e nomeada como tal era a categoria matronal, constituída pelas esposas legítimas dos cidadãos romanos. Vemos as matronas agirem coletivamente, quase como um corpo constituído" (BOËLS-JANSSEN, 2010, p.89). 
quadro institucional e moral romano, ou seja, nos quadros da religio romana. ${ }^{13}$ A etiologia é mimética, no sentido aristotélico da mimèsis tès praxèos, isto é, a personificação, a representação e a estilização da ação. Aristóteles analisa a mimèsis segundo três critérios distintos: os meios, os objetos e o modo de representação (Poet. 46a10-48b3), acentuando a ação cênica: a) do ponto de vista dos meios, especialmente sobre os aspectos não verbais, como os gestos, a mímica etc., observando a expressão ou o caráter "conativo" da linguagem; b) do ponto de vista dos objetos, observando seu lugar, posição e sentido no desenvolvimento do drama, ampliando seus aspectos expressivos e afetivos, e c) do ponto de vista do modo, a representação no sentido "dramático", narrativo, que é "posta em cena".

Os mitos etiológicos podem ser vistos como meios poderosos de instituir modos de ver o mundo e o lugar de cada coisa no mundo, veiculando os binômios antitéticos, como certo/errado, justo/injusto, adequado/inadequado, aceitável/inaceitável etc., que fundamentam sociedades fortemente hierarquizadas como a romana. Interessa, agora, observar, do ponto de vista dos meios, dos objetos e do modo de representação como a narrativa de Dionísio de Halicarnasso opera tal mimèsis, no contexto da restauratio augustana, trazendo à cena literária supplicationes marcadas pela estereotipia, pelo formalismo e pelo simbolismo (Holkeskamp, 2006, p.478-495; Benoist, 1999).

13 Roma se fundamentava nas leis e na religião, que apresentam as divindades como parceiras dos seres humanos (cf. Cic. Leg. 1, 27, 21; 2.10,26). Ultrapassar, contudo, o limite entre a preocupação religiosa com as obrigações e praticar uma atitude de temor irracional frente às divindades e suas prescrições era algo reprovável, a que Cícero, por exemplo, se referia com o termo superstitio, como na passagem qui totos dies precabantur et immolabant, superstitiosi sunt appelati (ND. II, 72). O grande problema, para Cícero, era a desmedida determinar o comportamento humano em relação às divindades. $\mathrm{O}$ ritual organiza as relações entre seres humanos e seres divinos, num quadro regular de ações e reações instituídas e normatizadas pela urbs. 


\section{SUPPLICATIONES EM CENA NO Mito da Fortuna MUliebris}

Os temas do mito do Coriolano nas Antiquitates de Dionísio, pela extensão da narrativa e pelas isotopias explícitas, podem ser divididos em dois eixos principais. Um primeiro eixo temático refere-se à criação da res publica, expresso pelas referências às conquistas territoriais, às relações entre povos latinos, aos limites, fronteiras e tratados. Um segundo eixo, que assoma com maior destaque, define-se pelas distinções, relações e papéis sociais de gênero assignados a homens e mulheres na sociedade romana (augustana), expressos pelas referências à domus, ao casamento, à maternidade e ao lugar social de homens e mulheres, euforizando-se o valor moral das únicas mulheres que interessam ao relato: as matronae. ${ }^{14}$ Ambos têm como ponto de encontro e fundamento o quadro institucional romano, simultaneamente político e religioso, ${ }^{15}$ expressando-se na linguagem dos rituais romanos, com destaque para as supplicationes que pontuam a narrativa.

O que é uma supplicatio? Em linhas gerais é uma procissão, e as procissões religiosas são elementos-chave no programa ritual romano. Mas, de que tipo de procissão se trata? A supplicatio se refere, antes de tudo, a uma prática processional que veicula um pedido formal ou um agradecimento por um favor, auxílio, perdão ou misericórdia, e que demanda resposta. Desse modo, ela se assemelha à precatio (prece), mas tal pedido e a consequente resposta dizem respeito, essencialmente, a seres humanos. Certamente os deuses estão envolvidos, mas a solicitação e a resposta são questões humanas e lidam com ações realizadas por seres humanos, e não por divindades. O termo principal da supplicatio, supplico, deriva de uma raiz que significa tanto "apaziguo" quanto "ajoelho", e o termo latino

14 Outros eixos temáticos são possíveis, por exemplo, o das relações entre patrícios e plebeus na construção da urbs, mas observá-lo não traz elementos significativos para esta análise.

15 Um aspecto importante da religião romana está contido no significado do próprio termo religio. Em linhas gerais, podemos dizer que o vocábulo indica o sentido de "constrangimento", "impedimento" que, pela proibição ou pelo temor reverencial, se expressa como "escrúpulo": cf. BELTRÃO, 2008, p.77-88. 
supplex ("ajoelhar-se") se refere ao gesto clássico dos suplicantes, assim como o cognato supplicium é um termo vinculado a culpa. ${ }^{16}$ Ressalte-se, contudo, que culpa, uma impiedade derivada de um erro, é perdoável, enquanto o maleficium e a iniuria não o são.

Uma excelente definição das supplicationes foi formulada por F.S. Naiden:

Quando comparada ao ritual que lhe é mais semelhante, a prece, a suplicação difere no que tange ao papel dos deuses. Na prece, os deuses são os destinatários. Na suplicação, um ser humano é o destinatário, ou, se o suplicante estiver diante de um altar, e os oficiantes do rito lhe respondem em nome de um deus, os oficiantes e o deus são, ambos, os destinatários. Mesmo nesta situação, na qual um deus é o destinatário, os deuses são figuras secundárias. Eles podem ser invocados num terceiro momento, quando um suplicante faz seu pedido e apresenta seus argumentos, e servem como garantias de qualquer oferta ou auxílio (...). Outra característica também distingue a suplicação da prece. $\mathrm{O}$ endereçado, na prece, está ausente. Na suplicação, o endereçado está presente. Por esta razão, a suplicação de um deus só é possível se o deus responde por uma epifania. (Naiden, 2006, p.7).

Segundo Naiden, a supplicatio emerge como uma prática com elementos legais, morais e religiosos, e o autor propõe um modelo útil para a análise dos rituais de supplicatio:

A despeito de diferenças ocasionais, esses atos têm quatro passos em comum. O primeiro passo é uma aproximação (física) de um indivíduo ou de um lugar. (...) Então, vem o segundo passo, o uso de um gesto distintivo. (...) O terceiro passo, a demanda de um benefício, é totalmente verbal. (...) O quarto e último passo é a resposta do suplicado. Ele avalia os suplicantes, decide se aceita ou rejeita o pedido. (Naiden, 2006, p.4).

16 BENVENISTE, 1969, p.250 ss; ERNOUT, MEILLET, 2001, p.669, s.v. supplex. 
A aproximação física, no primeiro passo, e os gestos, no segundo, são estereotipados, visando à sua univocidade, e a supplicatio tem as características da repetição e da formalidade que caracterizam os rituais em geral. Os dois primeiros passos, contato físico e performance gestual, são condições prévias sob as quais o suplicante ${ }^{17}$ apresenta sua demanda ao destinatário, o suplicado, que se fundamenta, no terceiro passo, em padrões morais, legais e religiosos compartilhados. A supplicatio é, portanto, uma ação de contato, gesto e discurso, atuando simultaneamente e, nela, a argumentação desempenha um importante papel, com base em argumentos legais e extralegais. Palavras e gestos são, então, media complementares para fins de comunicação e persuasão numa supplicatio. $\mathrm{O}$ ato de julgamento (o quarto passo), que também depende de valores e crenças compartilhadas, se caracteriza, para Naiden, por ser uma relação assimétrica de forças, mesmo que momentânea, e argumenta que "um suplicante tem de ser persuasivo, como convém a uma concepção retórica, mas também tem de ser confiável” (Naiden, 2006, p.26).

Nas extensas tabelas com índices de supplicationes na literatura antiga grega e romana que fornece, Naiden identifica, no episódio do Coriolano das Antiquitates de Dionísio de Halicarnasso, seis supplicationes, a saber: $\left.1^{\text {a }}\right)$ supplicatio do Coriolano a Átio Túlio (8.1.5 - 8.2.1); $2^{\text {a }}$ supplicatio dos tolerienses ao Coriolano (8.17.6); $3^{\text {a }}$ ) supplicatio dos labicanos ao Coriolano (8.19.4); $4^{\text {a }}$ ) supplicatio de Valéria e o coro das matronae a Vetúria $(8.40 .1$ - 8.43.2); 5a) supplicatio de Vetúria ao Coriolano (8.45.1 - 8.54.1); e 6 $6^{\text {a }}$ supplicatio dos volscos aos romanos (8.67.8). Destacam-se, pela extensão, pela quantidade de referências religiosas e pela dramaticidade a $4^{\text {a }}$ e a $5^{\mathrm{a}}$ supplicationes, o que apoia minha afirmação de que o segundo eixo temático, o eixo dos papéis sociais de gênero, é o ponto central do discurso.

17 A supplicatio pode ser uma intercessão em benefício de outra(s) pessoa(s). No caso do episódio em questão, há vários beneficiários de supplicationes e um beneficiário geral: Roma. Para Naiden: “... intercessoras bem-sucedidas são frequentemente mulheres. O modelo mítico dessas intercessoras é Justiça, sentada aos pés de Zeus em Hesíodo; o modelo épico é Thetis, implorando ao deus em favor de seu filho" (NAIDEN, 2006, p.41). 
Importa observar trechos do relato de Dionísio, a partir de 8.40.1, no início da $4^{\text {a }}$ supplicatio identificada por Naiden, a qual apresenta os elementos destacados nos quatro "passos" do ritual. Se no relato de Tito Lívio (II, 32-40) não há referência ao caráter da embaixada matronal - se foi uma decisão pública ou uma iniciativa privada - tampouco qualquer indicação de como as mulheres se reuniram para irem ao campo dos volscos, em Dionísio de Halicarnasso uma longa narrativa precede a ação das mulheres. Tal narrativa é centrada numa personagem inexistente em T. Lívio, Valéria, supostamente irmã de Valério Publícola. Com base no fato de que matronas romanas suplicavam nos templos pela salvação de Roma ("Todos os lugares sagrados estavam plenos de gemidos e súplicas de mulheres, sobretudo o templo de Júpiter Capitolino": 8.39.1), Valéria, a partir de uma "súbita inspiração", decide reunir as matronas, e as convence a se remeterem a Vetúria, mãe do agressor, para que esta tentasse dissuadi-lo:

(...) Vamos à casa de Vetúria, a mãe de Márcio, e, pondo as crianças a seus joelhos, peçamos com lágrimas que, por compaixão para conosco, que não somos responsáveis por nenhum mal, e pela pátria, que sofre os perigos mais extremos, vá ao acampamento dos inimigos com seus netos, com a mãe deles e com todas nós, pois devemos acompanhá-la com nossos filhos; então, que como suplicante peça e rogue a seu filho que não faça nada de irreparável contra a pátria; pois, quando ela chorar e suplicar, um sentimento de compaixão e uma consideração humana invadirão ao homem. Não tem um coração tão duro e invulnerável que possa suportar que sua mãe se jogue aos seus pés (8.39.4-5).

Esta seção é plena de referencias a atividades religiosas: a decisão de Valéria é inspirada pelos deuses, as matronas suplicavam nos templos pela salvação de Roma, as matronas suplicarão a Vetúria para que esta saia de sua posição de passividade, própria às mulheres, e aja em prol da cidade. As matronas - uma personagem coletiva - se autodeclaram "fracas", mas vão à domus do Coriolano ( $1^{\circ}$ passo), onde encontram Vetúria apropriadamente sentada no espaço doméstico, em companhia 
de sua nora, Volumnia. Neste momento, enquanto as mulheres fazem gestos de súplica, choram e se lamentam ( $2^{\circ}$ passo) Valéria discursa, apresentando seu pleito ( $3^{\circ}$ passo), pedindo explicitamente o auxílio dos deuses para que seu discurso fosse persuasivo (8.40.2-4):

Se há algo de humano e bondoso em alguma parte de tua alma, Vetúria, compadece-te, como mulher, das mulheres que uma vez compartilharam contigo sacrifícios e ritos e, tomando contigo a Volumnia, a boa mulher de Marcio, a seus filhos e a nós, suplicantes, que também somos de nobre nascimento, com essas crianças, vá junto a teu filho e trata de convencê-lo, roga-lhe com insistência e não deixes de suplicar-lhe, pedindo um único favor em troca de muitos: que faça a paz com seus concidadãos, e regresse à pátria que deseja recebê-lo; pois tu o convencerás, tenha-o por certo e, sendo um homem piedoso, não permitirá que tu estejas prostrada a seus pés (8.40.3).

Vetúria expressa dúvidas sobre sua capacidade de demover seu filho ("nós, as infelizes mulheres que, ainda que tenhamos boa disposição para com nossa pátria e boa vontade para salvar aos cidadãos, (...) carecemos de força e de poder para fazer o que queremos": 8. 41.1), e se nega a atender à súplica (4 ${ }^{\circ}$ passo), argumentando que seu filho, ao partir de Roma, declarara romper todos os laços com sua domus, mas, após nova investida de Valéria, bem como de um renovado lamento das mulheres presentes ("e tão grande gemido se apoderou da casa, que a gritaria se ouviu em boa parte da cidade": 8.41.2) (reiteração do $2^{\circ}$ e do $3^{\circ}$ passos), Vetúria, convencida, aceita e concorda em partir com as matronas ao encontro do Coriolano ( $4^{\circ}$ passo, resultando numa supplicatio bem sucedida).

As matronas demandam aos deuses o apoio e levam aos cônsules sua proposta de uma embaixada ao campo volsco (8.43.3). É apresentada uma longa discussão no Senado, na qual dúvidas sobre a pertinência de se confiar tal tarefa a mulheres são levantadas (8. 43.5-6). Em toda a seção, os limites da atuação feminina e declarações sobre as capacidades e competências "naturalmente" femininas pontuam o discurso, ressaltando seu poder de convencimento pelo choro e pelas lágrimas. 
Após a aprovação da missão das matronas pelo Senado, um decreto é lido à noite, no Comitium (8.43.7), e a embaixada das matronas é conduzida, oficialmente, às portas da cidade na madrugada seguinte:

Os cônsules, que haviam preparado mulas, carros e outros meios de transporte no maior número possível, as instalaram neles e as acompanharam por um bom trecho. E não apenas as acompanhavam os senadores, senão também muitos outros cidadãos, tornando ainda mais notável sua saída com suas invocações, louvores e súplicas (8.44.1).

Em 8, 44,2, a procissão das mulheres, percebida de longe, suscita surpresa e admiração no Coriolano. As matronas, personagem coletiva e coadjuvante, estão de luto, choram e se lamentam. As roupas são signa de fácil entendimento, por isso, muito “eloquentes". Além das palavras, gestos e vestuário da suplicante Vetúria, a performance das coadjuvantes potencializa o efeito das ações do ritual, no qual as matronas irrompem num espaço inscrito no polo masculino do discurso, o campo de batalha ( $1^{\circ}$ passo). Apresentando-se em procissão diante do Coriolano, após três embaixadas masculinas anteriores, a dos magistrados, dos senadores e dos sacerdotes, a supplicatio é encenada no relato como o modo de ação religiosa feminina par excellence.

Ao perceber a presença de sua mãe, Vetúria, entre as matronas que choram e gesticulam ( $2^{\circ}$ passo), o Coriolano exige que os volscos abaixassem suas armas ("Os romanos costumam fazer isso quando os que têm magistraturas inferiores saem ao encontro de magistrados superiores", 8.4.4). Vetúria, convidada a falar, "disse que falaria na presença de todos, pois não iria pedir nada ímpio, e lhe rogou que se sentasse no lugar onde costumava fazê-lo a fim de administrar a justiça às suas tropas" (8.45.2). É dito que ele exigiu que seu assento estivesse no mesmo nível que o da mãe e, sentado ao lado dos generais volscos, permitindo a quem quisesse poder permanecer no local, pediu a Vetúria que falasse (8. 45.3). Esses signa são marcas de deferência, bem como inserem a procissão das matronas no plano institucional romano, elevando Vetúria ao mesmo nível de uma embaixadora: "Tão grande era nele a 
consideração, o cuidado e o respeito à sua família" (8.44.4), ${ }^{18}$ inscrevendo o Coriolano na condição de pius, o que resgata o personagem da suspeita de "traição por impiedade".

O discurso de Vetúria $(8.46 ; 8.53 .4)$, o $3^{\circ}$ passo, é apresentado sob a forma de diálogo, entrecortado por uma interrupção do Coriolano (8.47.1-5), que argumenta pela impiedade de uma traição àqueles que o receberam como um dos seus e pelas aclamações dos volscos, ao que Vetúria retruca,

Márcio, meu filho, não peço que sejas um traidor para os volscos que te acolheram quando estavas desterrado e que, para além de outras honras, te confiaram o mando de suas tropas, nem quero que, contra os acordos e os juramentos que lhes prestaste quando tomaste a teu comando o exército, ponhas fim à inimizade por tua conta, sem o consentimento geral; e não creia que os deuses tenham infundido em tua mãe tanta loucura que exortasse seu amado e único filho a ações vergonhosas e ímpias. Ao contrário, te peço que renuncies à guerra com o consenso geral, após convencer aos volscos de que sejam moderados a respeito da reconciliação, e celebrem uma paz que seja boa e conveniente para ambos os povos (8.48.1-3).

Vetúria apresenta sua petição: que seu filho retirasse o exército do campo e concedesse uma trégua de um ano a Roma, abrindo as negociações com vistas à reconciliação (8.48.3-4). Se os volscos se opusessem, que ele renunciasse ao comando de seu exército, para não se converter num ímpio traidor de quem nele confiou, romanos ou volscos: "Isso é o que venho pedir-te, Márcio, meu filho, que não só não é impossível, como está livre de toda intenção injusta e ímpia” (8.48.5). E apresenta o argumento central de seu pedido: os laços que unem suplicante e suplicado, mãe e filho:

18 Sobre este tema ver: MUSTAKALLIO, 2011, p.41-76. 
Com efeito, tens de mim esses préstimos, e nenhum lugar, nenhum tempo os tirará de mim, nem os benefícios e favores dos volscos, nem de todos os demais homens serão tão poderosos, ainda que cheguem a ser altos como o céu, que aniquilem e deixem de lado os direitos da natureza. Para sempre serás meu, e a mim, antes que a qualquer um, me deverás o agradecimento por tua vida e me concederás a ajuda que te peço sem desculpas. Porque tudo isso é o que determina a lei da natureza para todos os que gozam de sentido e razão e, confiando nela, Márcio, meu filho, também te rogo que não leves a guerra à tua pátria, e serei obstáculo para ti se empregas a violência. Desse modo, ou com tua própria mão me sacrificas às Fúrias, a mim, tua mãe, que me oponho a ti, e empreendes então a guerra contra tua pátria, ou bem, envergonhando-se ante a impureza do matricídio, cedes a tua mãe e lhe concedes voluntariamente este favor. Assim, pois, contando como defensora e aliada e com esta lei que nenhum tempo destruirá jamais, não considero justo, Márcio, ver-me privada por ti das honras que esta me confere; mas, deixando a lei, considera de novo as lembranças dos bons feitos, pensando que são muitos e grandes. Quando teu pai te deixou órfão, encarreguei-me de ti, que eras uma criança pequena, e por ti permaneci viúva e sofri pacientemente os trabalhos que tu, criança, impunha, sendo para ti não só mãe, mas também pai, nutriz, irmã e tudo o mais querido. Quando te fizeste homem, ainda me era possível, então, liberar-me das preocupações casando-me com outro homem, criar novos filhos e depositar muitas esperanças na minha velhice; não quis, senão permaneci sob o mesmo lar, e me contentei com a mesma vida, centrando em apenas tu todos os meus prazeres e desejos, aqueles que, em parte involuntária, em parte voluntariamente, me defraudaste e fizeste de mim a mais desgraçada de todas as mães (8.51.2-4).

As palavras fornecem a justificativa da ação ritual e se baseia num laço entre o suplicante e o suplicado, neste caso, ditos determinados pela "lei da natureza", e apresentados como sagrados, pois protegidos pelas Fúrias. As demandas das supplicationes apelam aos laços sociais, seja um laço moral, legal, familiar, de amizade, e a valores compartilhados, pois 
só se tornam eficazes no interior das convenções sociais. Um argumento forte é a reciprocidade:

Esta toma duas formas: declarações de que o suplicado foi ajudado no passado pelo suplicante, e declarações de que o suplicante o ajudará no futuro, caso sua demanda for aceita. (...) Reivindicações de serviços prestados no passado começam com os serviços feitos a ele em sua infância. Mães expõem seus seios e dizem aos suplicados: "Eu te alimentei”, e as amas expõem os seus, dizendo "Eu alimentei ao rei". ${ }^{19}$

E o apelo patético é aumentado com a ameaça do suicídio e a súplica aos deuses:

Com efeito, Vetúria não suportará, depois de haver recebido o terrível e irreparável ultraje ante tantas testemunhas, viver o mais ínfimo tempo, senão que, diante dos olhos de todos vós, amigos e inimigos, dar-me-ei a morte, deixando-te em meu lugar uma pesada maldição e as terríveis Fúrias como vingadoras. Que não seja crime chegar a isso, ó deuses guardiães do poder dos romanos. Concedei pensamentos piedosos a Márcio, e que, como agora mesmo, ao se aproximar de mim, afastou os feixes e fez descer as lanças, fez descer o assento da tribuna e o deixou no chão, e todas as demais distinções com que é costume honrar-se aos magistrados com plenos poderes, a algumas diminuiu e a outras desfez de todo, querendo tornar evidente a todos que era justo que governasse aos demais, mas que sua mãe devia governá-lo, assim também agora que me outorgue honra e fama e, concedendo-me como um favor nossa pátria comum, me faça, em vez de a mais desgraçada, a mais afortunada das mulheres. E se é lícito e piedoso que uma mãe se arraste aos pés de seu filho, submeto-me, não só a isso, mas a qualquer outro comportamento e serviço humilhantes pela salvação da pátria (8.53.2-4).

19 NAIDEN, 2006, p.79. Observe-se que posteriormente Dion Cássio, em sua narrativa, faz Vetúria, depois de discursar, rasgar suas vestes e exibir seus seios, dizendo "Veja, meu filho, o colo que te trouxe à luz e os seios que te alimentaram" (V. 40), no clímax da cena. 
No caso das supplicationes, além dos gestos clássicos de ajoelhar-se ou prostrar-se aos pés do suplicado, beijar ou tocar seus pés, joelhos ou mãos são frequentes. Manter contato físico tem grande potencial expressivo, garantindo a comunicação não verbal. Vetúria pede permissão aos deuses para se prostrar diante de seu filho, se lança aos pés do Coriolano e os abraça e beija, enquanto o lamento das matronas aumenta em volume. Os volscos, consternados, não conseguem olhar a cena da mãe prostrada suplicando ao filho. O Coriolano, envergonhado, levanta de seu assento - saindo de sua posição de autoridade -, ergue sua mãe e a abraça, declarando-se "vencido": "Obténs, mãe, uma vitória que não é favorável nem a ti nem a mim, pois, por um lado, salvaste a pátria, mas, por outro, perdeste a mim, teu piedoso e amante filho" (8.54.1).

A dramatização do diálogo reforça o efeito patético da cena, que é potencializado pelas descrições dos gestos de Vetúria, os rumores dos volscos e os lamentos das matronas. Esses elementos, partes integrantes do "programa ritual" das supplicationes, têm grande destaque no livro em questão, escrito por um autor de língua grega nas primeiras décadas do principado augustano, que veicula uma versão da história arcaica romana na qual um modelo de matrona e da materfamilias ${ }^{20}$ assoma diretamente em relação com um ritual religioso, a fundação de um santuário e uma epifania da deusa, cuja "voz" garante às matronas: "Vós me consagrastes segundo as leis sagradas da cidade" (cf. digressão em 8.56.2). Mitos e rituais comunicam conteúdos e dão expressão a emoções, e tais emoções estão diretamente vinculadas à construção de identidades. É preciso, então, perguntar pelo mundo além do texto, o mundo ao qual o texto se destina.

\section{À guisa de Conclusão, Fortuna Muliebris, Lívia E A RESTAURATIO AUGUSTANA}

$\mathrm{Na}$ sociedade romana, os ordenamentos jurídico, familiar, político etc., tinham sua base no complexo sistema religioso romano, e já se destacou,

20 A matrona romana, i.e., a mulher casada, torna-se materfamilias após um parto bem-sucedido. 
coerentemente, o papel decisivo dos mitos na construção das identidades que, segundo Katherine Woodward, "são fabricadas por meio da marcação da diferença. Essa marcação de diferença ocorre tanto por meio dos sistemas simbólicos de representação, quanto por meio de formas de exclusão social" (Woodward, 2008, p.40). Os mitos etiológicos forneciam elementos para a constituição de potentes sistemas simbólicos, nos quais um passado comum era criado, diferenças eram sublinhadas e distinções eram marcadas. Tais mitos, ao ganharem formas cada vez mais patéticas e ao circularem no espaço público, potencializavam os rituais na definição do que era ser romano, garantindo à cidade uma aura sagrada $\mathrm{e}$ transformando suas formas de ordenamento social numa ordem sagrada (Paden, 1996, p.3-18), que inclui - como um de seus principais elementos - as distinções de gênero e seus respectivos papéis sociais:

As religiões proveem mitos e símbolos de origem e de criação, frequentemente oferecem narrativas de redenção e de salvação (...). Religiões criaram e legitimaram os gêneros, reforçaram-nos (...). Religião e gênero não são apenas análogos, existindo paralelamente uma ao outro no mesmo nível. Tampouco são duas realidades independentes que são simplesmente reunidas numa comparação simples, pois os padrões dinâmicos do gênero estão profundamente arraigados nas diversas religiões, fundidos e interestruturados nas experiências religiosas. Este arraigamento significa que o gênero é inicialmente difícil de identificar e separar de outros aspectos da religião. (King, 2004, p.71).

O mito etiológico do templo da Fortuna Muliebris, consolidado nas narrativas de Tito Lívio e Dionísio de Halicarnasso, é um dos mitos pelos quais a história, a identidade e o próprio espaço físico da urbs foram construídos no período augustano, inserindo-se na chamada restauratio augustana, um conjunto de ações religiosas, jurídicas e administrativas, intervenções arquitetônicas e artísticas no espaço da urbs e ressignificações de temas e imagens tradicionais que se constituiu como uma "revolução cultural” (Wallace-Hadrill, 2008; Wallace-Hadrill, 2005, p.55-84). $\mathrm{O}$ estudo do período augustano revela um grande investimento em 
rituais que ressaltavam elementos "arcaicos" ou arcaizantes, ligados à fundação de Roma ou da República romana - mesmo que se tratasse de inovações médio ou tardo-republicanas -, e numa literatura que promovia e reiterava o que era apresentado como o mos maiorum, ${ }^{21}$ que:

(...) se cristaliza em torno dessas figuras sob a forma de histórias personalizadas, incluindo muitos exempla, i.e., precedentes com força normativo-exemplar que podem ser utilizadas em todas as situações e a qualquer momento. Como corolário, esta visão do glorioso passado romano estava imbuída de uma "teologia da vitória" particular, que dotava as origens da cidade com uma aura religiosa. (Holkeskamp, 2006, p.481).

A restauração - ou a criação - do templo da Fortuna Muliebris por Lívia (CIL. VI, 883), coincide com a inauguratio dos novos vici (grosso modo, "bairros") e das regiones, no âmbito reforma urbana e suburbana promovida pelo governo augustano (Lott, 2004), (Haselberger, 2007). O templo e o mito da Fortuna Muliebris são, interligados, uma das criações mais bem-sucedidas do período, reforçando a ideia de um ager romanus antiquus, uma fronteira "arcaica" para Roma, um cinturão de templos e santuários ora "restaurados", ora criados a fundamento, sacralizando a urbs e o poder de Augusto, além de prover um apoio sólido para as ações relativas à tão propalada "restauração" da "moralidade pública", com as leis relativas ao casamento e à vida familiar no principado augustano. ${ }^{22}$ Neste ponto, o papel de Lívia, matrona-modelo e promotora das virtudes matronais, se destaca, provendo valores "tradicionais" que tanto instituíam uma paisagem religiosa para a Roma augustana como reforçavam a lógica (androcêntrica) dos papéis de gênero, ao promover o prestígio de matronas que honravam "seu papel" e que, por tal, garantiam a salvação da pátria.

21 HABINEK, 1998, especialmente capítulo 1.

22 As referências, aqui, são a Lex Iulia de Maritandis Ordinibus (18 a.E.C.), a Lex Iulia de Adulteriis Coercendis (18 a.E.C.) e a subsequente Lex Papia Poppeae (9 a.E.C,); cf. GALINSKY, 1981, p.126-144 e TREGGIARI, 1991. 
A matrona, a família e o casamento exigem um marco mais amplo para o seu estudo, tendo em conta sua relação com o âmbito religioso, e são, ambos, elementos centrais da restauratio augustana, que não operava num vacuum. A família patriarcal romana era um agrupamento de pessoas livres e não livres que implicava propriedade, patrimônio e herança, e o controle imperial desta instituição interessava às elites romanas. Do mesmo modo, o laço religioso era o fundamento da família, e o casamento era a uma instituição estabelecida pela religião doméstica, instituição que significava a passagem da mulher de um culto - o da família de seu pai - a outro - o da família de seu marido. E a mulher, no casamento, garantia a continuidade, por meio da geração de filhos homens, do culto dos maiores. Do fundamento religioso do casamento se depreende a ênfase na desejada castidade feminina, que não corresponde à virgindade, e sim à proibição às mulheres do adultério, da poligamia e sua necessária restrição ao espaço da domus, já que a matrona, por procriar filhos legítimos para a familia de seu marido, não podia pertencer a mais de um culto familiar. A sacralidade dessa instituição é reforçada e propalada na urbs augustana, daí a força dos mitos nos quais se apresenta uma intervenção feminina "excepcional" no espaço público (Valette, 2012), em prol da sacralidade dos laços familiares patriarcais e da manutenção do espaço da domus.

A exaltação da virtus e da traditio como valores centrais se traduzia na necessidade de controle do elemento feminino da urbs, que deveria se vincular a um homem pelo casamento e gerar herdeiros legítimos para a domus a que pertencia, filhos que eram sua "razão de ser" e pelos quais seu estatuto social era garantido, numa espécie de "administração do feminino" que surge como absolutamente necessária para a manutenção dos mores, que ganha, sob Augusto, força de lei. E a força normativo-exemplar das narrativas etiológicas junto com os rituais do calendário religioso oficial, fomentava um processo educativo no qual os papéis de gênero eram veiculados, encenados, aprendidos e incorporados, tornando-se 
naturais. ${ }^{23} \mathrm{Na}$ narrativa de Dionísio, uma hierarquia institucionalizada, baseada em relações assimétricas de gênero, tanto em termos de organização institucional quanto de representação social ensinava aquilo que era aprovado pelas divindades, desejável socialmente, motivo de elogios e vantagens legais - e, obviamente, o que era reprovável, indesejável, punível ou, mesmo, impensável.

\section{REFERÊNCIAS BIBLIOGRÁFICAS}

ALFÖLDI, Andreas. Early Rome and the Latins. Ann Arbor: University of Michigan Press, 1965.

BEARD, Mary A. Complex of Times: No More Sheep on Romulus' Birthday. In: ANDO, C. (ed.). Roman Religion. Edinburgh: Edinburgh University Press, 2003. p.273-288.

BEARD, Mary; NORTH, John A.; PRICE, Simon R.F. Religions of Rome, vol. 1 (A History). Cambridge: Cambridge University Press, 1998.

BELL, Catherine. Ritual. Perspectives and Dimensions. New York: Oxford University Press, 2009.

BELL, Catherine. Ritual Theory, Ritual Practice. New York: Oxford University Press, 1992.

BELTRÃO, Claudia. Considerações em torno de religio em suas manifestações literárias. In: LIMA, Alexandre. C. C.; TACLA, Adriene B. (orgs.). Experiências Politeístas. Cadernos do CEIA, ano I, n.1. Niterói: Centro de Estudos Interdisciplinares da Antiguidade (CEIA/UFF), p.77-88, 2008. BELTRÃO, Claudia. Constructing sacred boundaries to Rome: Augustus and the ager romanus antiquus. In: ZUIDERHOECK, A.; VAN NUFFELEN, P. (ed.). Imperial Identities in the Roman World. Farnham: Ashgate Publishing Ltd., no prelo.

23 cf. a tese de Judith Butler do gênero como performativo, resultando numa identidade que, longe de ser uma concretização de quaisquer distinções biológicas, é uma construção social e culturalmente contingente, contudo, naturalizada pelas práticas e discursos sociais: BUTLER, 1990, p.25 ss. 
BELTRÃO, Claudia. Fortuna Muliebris: um mito augustano (Tito Lívio, Ab urbe condita, II, 39-40). Phoînix, vol. 19, n.1, p.108-126, 2013.

BELTRÃO, Claudia. Terminalia: fronteiras e espaço sagrado. Phoînix, vol. 17, n.2, p.82-99, 2011.

BENOIST, Stéphane. La fête à Rome au premier siècle de l'Empire. Recherches sur l'univers festif dous les régnes d'Auguste et les JulioClaudiens. Bruxelles: Latomus, 1999.

BENVENISTE, Émile. Le vocabulaire des instituitions indo-européennes, Vol. 2: Pouvoir; Droit; Religion. Paris: Les Éditions de Minuit, 1969.

BOËLS-JANSSEN, Nicole. Matrona/Meretrix: Duel ou duo? À propos du rôle social et religieux des grandes catégories féminines dans l'imaginaire romain. In: BRIQUEL, D.; FÉVRIER, C.; GUITTARD, Ch. (Eds.). Varietatis Fortunae. Religion et mythologie à Rome. Paris: Presses de l'Université Paris-Sorbonne, 2010. p.89-129.

BUTLER, Judith. Gender Trouble: Feminism and Subversion of Identity (Thinking Gender). New York: Routledge, 1990.

CIFANI, Gabriele. Roma. Una Stipe Votiva al IV Miglio tra le Vie Latina e Labicana. Mélanges de l'école francaise de Rome, vol. 117, n.1, p.199-221, 2005.

DOUGLAS, Mary. Natural Symbols. Explorations in Cosmology. New York: Routledge, 1996.

ERNOUT, Alfred; MEILLET, Antoine. Dictionnaire étymologique de la langue latine. Histoire des Mots. Paris: Klincksieck, 2001.

GALINSKY, Karl. Augustus Legislation on Morals and Marriage. Philologus, n. 125, p.126-144, 1981.

GARGOLA, Daniel J. Lands, Laws and Gods. Magistrates and Ceremony in the Regulation of Public Lands in Republican Rome. Chapel Hill: University of North Carolina Press, 1995.

GEERTZ, Clifford. A Religião como Sistema Cultural. In: GEERTZ, C. A interpretação das culturas. Rio de Janeiro: LTC, 2008. p.65-91.

HABINEK, Thomas. The Politics of Latin Literature. Writing, Identity and Empire in Ancient Rome. Princeton: Princeton University Press, 1998. 
HASELBERGER, Lothar. Urbem adornare. Die Stadt Rom und ihre Gestaltumwandlung unter Augustus/Rome's Urban Metamorphosis under Augustus. Portsmouth, R.I.: Journal of Roman archaeology, supplementary series 64, 2007.

HÖLKESKAMP, Karl J. History and Colletive Memory in the Middle Republic. In: ROSENSTEIN, N.; MORSTEIN-MARX, R. (ed.) Companion to Roman Republic. Oxford: The Blackwell Publishing Ltda., 2006. p.478-495.

KING, Ursula. Religion and Gender: Embedded patterns, interwoven frameworks. In: MEDDE, T.A; WIESNER-HANKS, M.E. (ed.). A Companion to Gender History. Oxford: The Blackwell Publishing Ltd., 2004. p.70-85.

LOTT, John B. The Neighborhoods of Augustan Rome. New York: Cambridge University Press, 2004.

MUSTAKALLIO, Katharina. Representing Older Women: Hersilia, Veturia, Virgo Vestalis Maxima. In: KRÖTZL, C.; MUSTAKALLIO, K. (ed.). On Old Age. Approaching Death in Antiquity and the Middle Ages. Tournhout: Brepols Publishers, 2011. p.41-76.

NAIDEN, Fred S. Ancient Supplication. New York: Oxford University Press, 2006.

PADEN, William E. Sacrality as Integrity: "Sacred Order" as a Model for Describing Religious Worlds. In: INDINOPULOS, Thomas Q.; YONAN, Edward A. (ed.). The Sacred and its Scholars: Comparative Methodologies for the Study of Primary Religious Data. Leiden: Brill, 1996. p.3-18.

QUILICI-GIGLI, Stefania. Annotazioni topografiche sul tempio della Fortuna Muliebris. Mélanges de l'École Française de Rome, vol. 93, n.2, p.547-563, 1981.

SCHEID, John. Cults. Les sanctuaires de confins dans la Rome antique. Réalité et permanence d'une réprésentation idéale de l'espace romain. In: L'urbs: espace urbain et histoire (Ier siècle av. J. -C - IIIe siècle ap. J. -C.). Actes du Coloque International de Rome (8-12 mai.1985). Rome: École française de Rome, p.583-595, 1987. 
SCHEID, John. Cults. Myths and Politics at the Beginning of the Empire. In: ANDO, C. (ed.). Roman Religion. Edinburgh: Edinburgh University Press, 2003. p.117-146.

SCHEID, John; DE POLIGNAC, François. Qu'est-ce qu'un "paysage religieux"? Représentations cultuelles de l'espace dans les sociétés anciennes. Avant-Propos. Revue de l'histoire des religions, n.4, p.427-434, 2010. Disponível em: http://rhr.revues.org/7656; Acesso em: 11 dez. 2012.

SMITH, Jonathan Z. To Take Place: Toward Theory in Ritual. Chicago: University of Chicago Press, 1992.

TAMBIAH, Stanley. Culture, Thought and Social Action: an Anthropological Perspective. Cambridge-MA: Harvard University Press, 1985.

TREGGIARI, Susan. Roman Marriage. New York: Oxford University Press, 1991.

VALETTE, Emanuelle. Les “discours" de Veturia, Valeria et Hersilia. Les mises em scène de la parole matronale dans la tradition historiographique romaine. Cahiers “Mondes Anciens", n.3, 2012. Disponível em: http:// mondesanciens.revues.org/index782.html; Acesso em: 20 out. 2012.

WALLACE-HADRILL, Andrew. Mutatas formas: The Augustan Transformation of Roman Knowledge. In: GALINSKY, Karl. The Cambridge Companion to the Age of Augustus. New York: Cambridge University Press, 2005. p.55-84.

WALLACE-HADRILL, Andrew. Rome's Cultural Revolution. New York: Cambridge University Press, 2008.

WHITEHOUSE, Harvey; MARTIN, Lothar H. (ed.). Theorizing Religious Past. Archaeology, History, and Cognition. Walnut Creek: Altamira Press, 2004.

WHITEHOUSE, Harvey; McCAULEY, Robert N. (ed.). Mind and Religion. Psychological and Cognitive Foundations of Religiosity. Walnut Creek: Altamira Press, 2005.

WOODWARD, Katherine. Identidade e diferença: uma introdução teórica e conceitual. In: SILVA, T.T. (org.). Identidade e Diferença. A perspectiva dos Estudos Culturais. Petrópolis: Vozes, 2008. p.7-72.

ZIÓLKOWSKI, Adam. Frontier Sanctuaries of the ager romanus antiquus: did they exist?. Palamedes, vol. 4, n.1, p.91-130, 2009. 